\title{
Binary Vector Construction for Site-Directed Mutagenesis of Kafirin Genes in Sorghum
}

\author{
Grigoriy A. Gerashchenkov¹, Lev A. Elkonin2, Kirill G. Gerashchenkov³, Natalia A. Rozhnova1, \\ Stefan Hiekel ${ }^{4}$, Jochen Kumlehn ${ }^{4}$, Alexey V. Chemeris ${ }^{1}$
}

\author{
${ }^{1}$ Institute of Biochemistry and Genetics, Subdivision of the Ufa Federal Research Centre of the Russian Academy of Sciences, Ufa, \\ Russia \\ ${ }^{2}$ Federal Centre of Agriculture Research of South-East Region, Saratov, Russia \\ ${ }^{3}$ Kazan Federal University, Institute of Fundamental Medicine and Biology, Kazan, Russia \\ ${ }^{4}$ Leibniz Institute of Plant Genetics and Crop Plant Research (IPK), Gatersleben, Germany \\ Email: ^lelkonin@gmail.com
}

How to cite this paper: Gerashchenkov, G.A., Elkonin, L.A., Gerashchenkov, K.G., Rozhnova, N.A., Hiekel, S., Kumlehn, J. and Chemeris, A.V. (2021) Binary Vector Construction for Site-Directed Mutagenesis of Kafirin Genes in Sorghum. American Journal of Plant Sciences, 12, 1276-1287. https://doi.org/10.4236/ajps.2021.128089

Received: July 5, 2021

Accepted: August 27, 2021

Published: August 30, 2021

Copyright $\odot 2021$ by author(s) and Scientific Research Publishing Inc. This work is licensed under the Creative Commons Attribution International License (CC BY 4.0).

http://creativecommons.org/licenses/by/4.0/

(c) (i) Open Access

\begin{abstract}
Sorghum (Sorghum bicolor (L.) Moench) is one of the world's leading cereal crops in agricultural production, which has a special importance in the arid regions. However, unlike other cereals, sorghum grain has a lower nutritional value, which is caused, inter alia, by the resistance of its seed storage proteins (kafirins) to protease digestion. One of the effective approaches to improve the nutritional value of sorghum grain is to obtain mutants with partially or completely suppressed synthesis or altered amino acid composition of kafirins. The employment of genome editing may allow to solve this problem by introducing mutations into the nucleotide sequences of the $\alpha$ - and $\gamma$-kafirin genes. In this study, genomic target motifs (23 bp sequences) were selected for the introduction of mutations into the $\alpha$ - and $\gamma$-KAFIRIN genes of sorghum. The design of the gRNAs was conducted using the online tools CRISPROR and CHOPCHOP. Two most suitable targets were chosen for $\alpha$-KAFIRIN $(k 1 C 5)$ and two for $\gamma$-KAFIRIN ( $g K A F 1)$ genes. The insertion of respective sequences in the generic vector pSH121 was performed at the BsaI (Eco31l) sites. Validation of the cloning procedure was performed by DNA sequencing. Subcloning of the resulting constructs was performed using the SfiI restriction sites into the compatible binary vector B479p7oUZm-LH. The correct assembly of binary vectors was confirmed by restriction analysis using the MluI and SfiI cleavage sites. The four vectors created (1C - 4C) were transferred by electroporation into the Agrobacterium tumefaciens strain AGL0. Currently, this vector series is used for stable transformation of sorghum using immature embryo explants.
\end{abstract}




\section{Keywords}

Sorghum bicolor (L.) Moench, CRISPR/Cas, Genome Editing, $\alpha$-Kafirin, $\gamma$-Kafirin, Genetic Engineering, Grain Quality

\section{Introduction}

Among the many biotechnological approaches for improving the properties of agricultural plants, genome editing has the potential to play a key role. Unlike traditional strategies and breeding methods, Cas endonuclease technology provides a fast path to the creation of modified genotypes through site-directed mutagenesis or precise editing of the nucleotide sequences of respective genes [1] [2]. To date, this technology allowed to modify many agronomically important traits in major cultivated crops, such as corn, rice, wheat, potatoes, soybeans, sugarcane, etc. [3] [4].

Sorghum (Sorghum bicolor (L.) Moench) is one of the most important droughttolerant cereal crops in the arid regions of the Earth. Due to global warming of climate, the importance of this crop is expected to grow steadily. Sorghum grains do not contain gluten and can serve as a source of protein for people with gluten intolerances, which must follow a gluten-free diet. However, compared to other cereals, sorghum grain has a lower nutritional value, the main reason for which is the resistance of its grain storage proteins (kafirins) to protease digestion [5] [6] [7]. The poor digestibility of kafirins, in turn, reduces the access of amylolytic enzymes to starch granules and reduces the digestibility of starch and the nutritional value of sorghum grain [8].

Cas endonuclease technology offers to solve this problem. The targeted induction of mutations in genes encoding different classes of kafirins, including gene knockouts, using genome editing bears the potential to significantly improving the digestibility of proteins in sorghum grain and increase its nutritional value. The reduction of kafirin synthesis induces the changes in the ultrastructure of endosperm protein bodies and increases their digestibility by proteases [9] [10] [11]. As a further consequence, the proteome of caryopses may be rebalanced via enhanced synthesis of other proteins [10], including those with a higher content of essential amino acids such as lysine [11] [12]. Recently published work on the induction of mutations in the $\alpha$-kafirin nucleotide sequence has shown the potential of Cas endonuclease technology to improve the nutritional value of sorghum grain [13].

Previous studies have revealed a multitude of aspects that have to be considered when generating transformation vectors for plant genome editing using Cas endonucleases [14] [15] [16]. The aim of this work was to create highly efficient vectors and agrobacterial clones containing these vectors to mutate the $\alpha$ and $\gamma$-KAFIRIN genes of sorghum. Accordingly, major features of the constructs generated in the present study include the rice $U_{3}$ promoter and the maize 
POLYUBIQUITIN 1 ( UBI1) promoter to drive gRNA (guide RNA) and cas9 expression, respectively. Further, the Phosphinothricin phosphotransferase (Bar) gene of Streptomyces hygroscopicus equipped with an intron to prevent agrobacterial expression and driven by the maize $U B I 1$ promoter was used as plant selectable marker.

\section{Materials and Methods}

pSH121 (NCBI: txid2338066) (Figure 1(a)) [17] was used as the basic vector for the introduction of target-specific sequences of kafirin-encoding genes upon

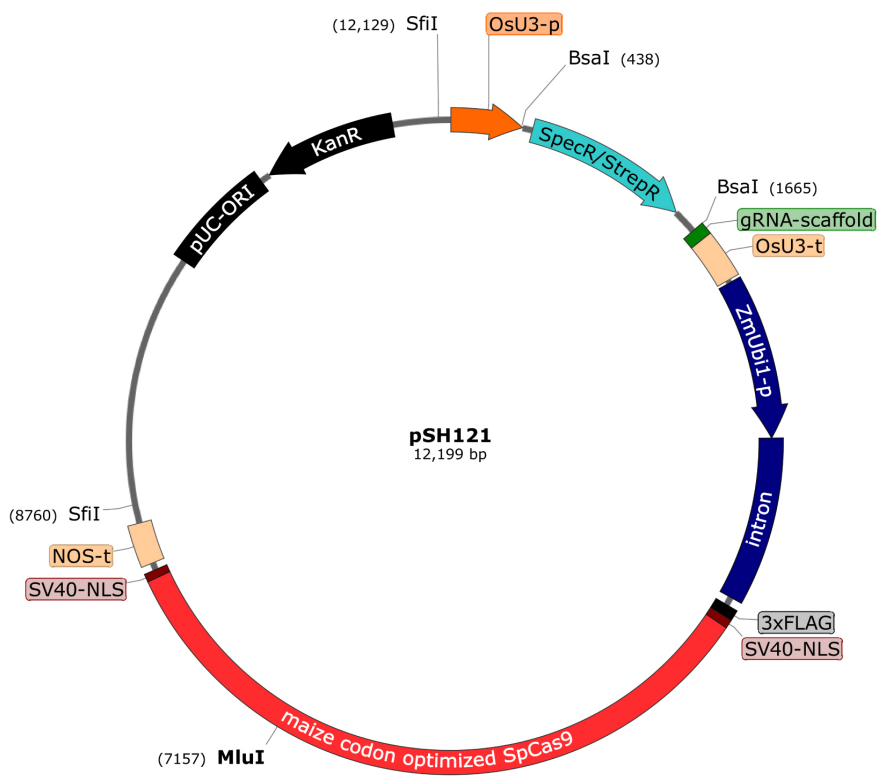

(a)

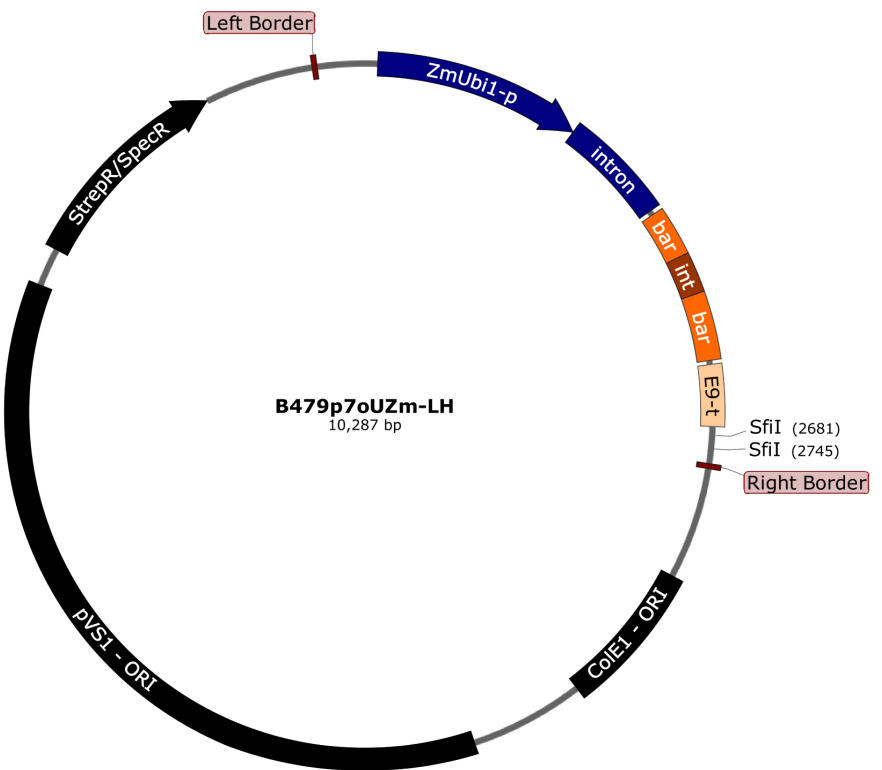

(b)

Figure 1. Vectors pSH121 (a) and B479p7oUZm-LH (b) used in this work. 
cleavage with BsaI to complement the gRNA expression units. This vector contains the nucleotide sequence of a maize codon-optimized cas 9 gene under control of the maize $U B I 1$ promoter and sites for the SfiI restriction enzyme for the directed transfer of a fragment containing the cas 9 and gRNA expression units into a binary vector of the p7i series. As a binary vector from this series, we chose B479p7oUZm-LH (Figure 1(b)) which contains the bar gene and also carries the SfiIA and SfiIB sites compatible with pSH121. This vector was purchased from DNA Cloning Service (https://www.dna-cloning.com/). Bioinformatics analysis of the nucleotide sequences of the pSH121 and B479p7oUZm-LH vectors was performed using the SnapGene Viewer software.

The genomic sequences of the $\alpha$ - and $\gamma$-KAFIRIN genes were taken from the site https://phytozome.jgi.doe.gov ( $\alpha$-KAFIRIN (k1C5): Sobic.005G193100, Chr05: 67654898 ... 67655764; $\gamma$-KAFIRIN (gKAF1): Sobic.002G211700, Chr02:

$60423442 \ldots 60424313)$. The selection of target motifs was carried out using the online tools CRISPOR (http://crispor.tefor.net/) and CHOPCHOP (https://chopchop.cbu.uib.no/) [18] [19].

For molecular cloning, conventional techniques were used if not specified otherwise [20]. The restriction endonucleases Eco31I, MluI and SfiI were purchased from Thermo Scientific. Restriction endonuclease SfiI is unique in that it recognizes a 13-nucleotide site and forms sticky ends, which is particularly useful to transfer DNA fragments in directed fashion. Fractionation of linearized plasmid DNA was carried out in agarose gel in $1 \mathrm{x}$ TAE buffer. Subsequent purification of DNA was performed using the ISOLATE II PCR and Gel Kit (BIOLINE) along with Quantum PrepTM Freeze'N Squeeze DNA Gel Extraction Spin Columns (Bio-Rad Laboratories). Ligation of targets and plasmids with 5' and 3'-overhangs was performed using T4 DNA ligase (Thermo Scientific). The created constructs were introduced into $E$. coli XL-1 Blue bacterial cells. The presence of target-specific inserts was monitored by DNA sequencing on an $\mathrm{ABI}$ 3130 genetic analyzer using the OsU3p-F3 sequencing primer

GACAGGCGTCTTCTACTGGTGCTAC. To validate the correct assembly of the cloned binary plasmids, restriction endonuclease analysis was performed using the enzymes MluI and SfiI. The created vectors were transferred by electroporation into the $A$. tumefaciens strain AGL0.

\section{Results and Discussion}

Transformation vectors for site-directed mutagenesis of kafirin genes were created by the following steps:

1) Retrieve kafirin gene sequences from databases and select target motifs within their coding sequences.

2) Clone the target-specific parts of the gRNAs into the generic vector pSH121.

3) Perform the verification of cloned DNA targets by sequencing.

4) Subclone a fragment containing the cas 9 and gRNA expression units into the generic binary vector B479p7oUZm-LH. 
5) Perform restriction endonuclease analysis to confirm the correct generation of vectors.

The genetic maps of the pSH121 and B479p7oUZm-LH vectors used in this study are shown in Figure 1.

\subsection{Bioinformatics Analysis and Oligonucleotide Design for the gRNA Expression Units}

Signal sequences play an important role in the packaging of kafirins into protein bodies, and, consequently, in the accumulation of storage proteins in sorghum grain. For example, a single nucleotide substitution $(\mathrm{G} \rightarrow \mathrm{A})$ at position 61 relative to the first nucleotide of the start codon of $\alpha$-KAFIRIN gene distinguishes the $h d h l$ mutant with a high digestibility of kafirins and high lysine content from other sorghum varieties [21]. This missense mutation results in the amino acid alanine (Ala) instead of a threonine (Thr) at the last position of the signal peptide. This mutation is thought to render the protein resistant to processing and to trigger the unfolded protein response (UPR) and the formation of irregular protein bodies [21]. Therefore, we chose nucleotide sequences of these parts of $\alpha$ - and $\gamma$-kafirins as target motifs for the RNA-guided Cas9 used in this study.

Using the CRISPOR and CHOPCHOP online tools to analyze the $63 \mathrm{bp}$ signal sequence of $\alpha$-kafirin made it possible to identify four target motifs, from which the two with the best features, such as specificity score, predicted efficiency, outcome of out-of-frame mutations and number of off-targets, were selected (Table 1). The same procedure was pursued for the $57 \mathrm{bp}$ signal sequence of $\gamma$-kafirin, which revealed five target motifs, from which another two were selected (Table 2). The results provided by the two platforms were very similar and therefore, only the data delivered by the CRISPOR tool are shown here.

The nucleotides of the signal sequences of $\alpha$-KAFIRIN (k1C5) and $\gamma$-KAFIRIN $(g K A F 1)$ genes with the location of target sites are shown in the scheme (Figure 2).

Table 1. Selection of target motifs within the signal peptide-encoding sequence of the $\alpha$-KAFIRINgene using the CRISPOR online tool.

\begin{tabular}{|c|c|c|c|c|c|c|c|c|}
\hline \#\# & Position/Strand & Target motif & $\begin{array}{c}\text { MIT } \\
\text { Specificity } \\
\text { Score }\end{array}$ & $\begin{array}{l}\text { CFD } \\
\text { Spec. } \\
\text { score }\end{array}$ & $\begin{array}{l}\text { Predicted } \\
\text { Efficiency, } \\
\text { Doench'16 }\end{array}$ & $\begin{array}{c}\text { Predicted } \\
\text { Efficiency, } \\
\text { Mor.-Mateos }\end{array}$ & $\begin{array}{c}\text { Outcome } \\
\text { Out-of-Frame }\end{array}$ & $\begin{array}{c}\text { Off-targets for } \\
0-1-2-3-4 \\
\text { mismatches }\end{array}$ \\
\hline 1 & $8 / \mathrm{rev}$ & CGCAAGGAGGACAAATATCT TGG & 17 & 86 & 39 & 39 & 61 & $\begin{array}{c}3-2-9-6-89 \\
109 \text { off-targets }\end{array}$ \\
\hline 2 & $33 / \mathrm{rev}$ & TTGTGCTCACTGAAAGAGCA $\underline{\text { AGG }}$ & 9 & 86 & 61 & 51 & 64 & $\begin{array}{c}8-2-5-4-27 \\
46 \text { off-targets }\end{array}$ \\
\hline 3 & $21 / \mathrm{rev}$ & AAAGAGCAAGGAGCGCAAGG $\underline{\text { AGG }}$ & 8 & 72 & 67 & 57 & 46 & $\begin{array}{l}11-4-3-16-131 \\
165 \text { off-targets }\end{array}$ \\
\hline 4 & $24 / \mathrm{rev}$ & CTGAAAGAGCAAGGAGCGCA AGG & 7 & 86 & 51 & 64 & 43 & $\begin{array}{c}10-4-3-3-27 \\
47 \text { off-targets }\end{array}$ \\
\hline
\end{tabular}

The $63 \mathrm{bp}$ input sequence ATGGCTACCAAGATATTTGTCCTCCTTGCGCTCCTTGCTCTTTCAGTGAGCACAACAACTGCA was used from Sorghum bicolor (pz9Sbicolor), chromosome_5:58133820-58133882, reverse genomic strand. It contains four possible target motifs. Expected cleavage positions are located -4 to -3 bp upstream of the Cas9-bound triplet (PAM). 
Table 2. Selection of target motifs within the signal peptide-encoding sequence of the $\gamma$-KAFIRINgene using the CRISPOR online tool.

\begin{tabular}{|c|c|c|c|c|c|c|c|c|}
\hline \#\# & Position/Strand & Target motif & $\begin{array}{c}\text { MIT } \\
\text { Specificity } \\
\text { Score }\end{array}$ & $\begin{array}{l}\text { CFD } \\
\text { Spec. } \\
\text { score }\end{array}$ & $\begin{array}{l}\text { Predicted } \\
\text { Efficiency, } \\
\text { Doench'16 }\end{array}$ & $\begin{array}{c}\text { Predicted } \\
\text { Efficiency, } \\
\text { Mor.-Mateos }\end{array}$ & $\begin{array}{c}\text { Outcome } \\
\text { Out-of-Frame }\end{array}$ & $\begin{array}{c}\text { Off-targets for } \\
0-1-2-3-4 \\
\text { mismatches }\end{array}$ \\
\hline 1 & $32 / \mathrm{fw}$ & GCTCGTTGCCCTCGCTCTCC $\underline{\text { TGG }}$ & 94 & 97 & 37 & 22 & 53 & $\begin{array}{c}0-0-0-7-37 \\
44 \text { off-targets }\end{array}$ \\
\hline 2 & $41 / \mathrm{fw}$ & CCTCGCTCTCCTGGCTCTCG CGG & 89 & 93 & 57 & 42 & 58 & $\begin{array}{c}0-0-1-15-94 \\
110 \text { off-targets }\end{array}$ \\
\hline 3 & $30 / \mathrm{rev}$ & $\begin{array}{l}\text { CGGCGCTCGCCGCGAGAGCC AGG } \\
\text { (high GC content) }\end{array}$ & 84 & 83 & 32 & 59 & 53 & $\begin{array}{l}0-0-0-8-125 \\
133 \text { off-targets }\end{array}$ \\
\hline 4 & $20 / \mathrm{rev}$ & CGCGAGAGCCAGGAGAGCGA GGG & 77 & 88 & 54 & 51 & 40 & $\begin{array}{c}0-0-0-14-151 \\
165 \text { off-targets }\end{array}$ \\
\hline 5 & $21 / \mathrm{rev}$ & CCGCGAGAGCCAGGAGAGCG AGG & 59 & 80 & 49 & 59 & 41 & $\begin{array}{c}0-0-2-9-259 \\
270 \text { off-targets }\end{array}$ \\
\hline
\end{tabular}

The 57 bp input sequence ATGAAGGTGTTGCTCGTTGCCCTCGCTCTCCTGGCTCTCGCGGCGAGCGCCGCCTCC was used from Sorghum bicolor (pz9Sbicolor), chromosome_2:60425298-60425354, forward genomic strand. It contains five possible target motifs. Expected cleavage positions are located -4 to -3 bp upstream of the Cas9-bound triplet (PAM).

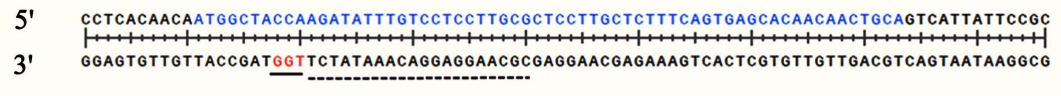

(a)

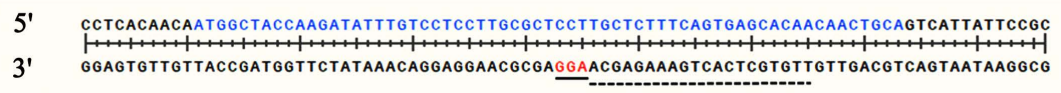

(b)

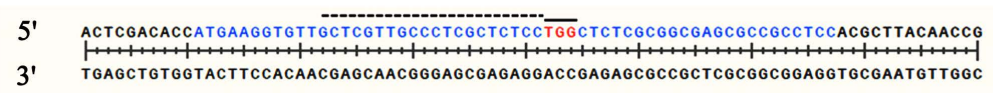

(c)

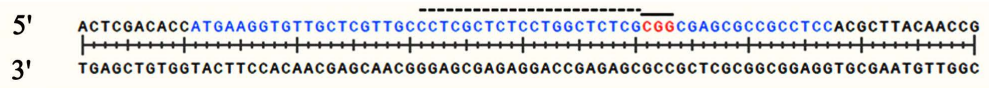

(d)

Figure 2. The nucleotides of signal sequences (highlighted in blue) of $\alpha$-KAFIRIN ( $k 1 C 5)$ ((a), (b)) and $\gamma$-KAFIRIN ( $g K A F 1)((\mathrm{c})$, (d)) genes with the location of PAM sites (underlined with a solid line) and selected target motifs (underlined with a dotted line).

According to the chosen target motifs, oligonucleotides were designed for subsequent cloning of gRNA/cas 9 vectors. The sequences of the oligonucleotides are shown in Table 3.

\subsection{Design and Cloning of gRNA/Cas9 Vectors}

Canonical target motifs for $U_{3}$ promoter-driven guide RNAs and Cas9 have the generic sequence $\mathrm{AN}_{19} \mathrm{NGG}$ (encompassing the target motif-specific part of gRNA and the PAM (protospacer adjacent motif)). For efficient transcription of gRNA under the control of the RNA polymerase III-processed OsU3 promoter, 
Table 3. Targets of kafirin genes used in the work.

\begin{tabular}{|c|c|c|c|}
\hline $\begin{array}{c}\text { Target } \\
\text { motif no. }\end{array}$ & $\begin{array}{c}\text { Target-specific } \\
\text { oligo name }\end{array}$ & $\begin{array}{l}\text { Nucleotide sequence } \\
\text { of target-specific oligo }\end{array}$ & $\begin{array}{l}\text { Name and target gene } \\
\text { of the resultant vector }\end{array}$ \\
\hline \multirow[t]{2}{*}{1} & a8r_F & TGGCAcgcaaggaggacaaatatct & 1C ( $\alpha$-KAFIRIN editing $)$ \\
\hline & $\alpha 8 \mathrm{r} \_\mathrm{R}$ & AAACagatatttgtcctccttgcgT & \\
\hline \multirow[t]{2}{*}{2} & $\alpha 33 r_{-} F$ & TGGCAttgtgctcactgaaagagca & 2C ( $\alpha$-KAFIRIN editing $)$ \\
\hline & $\alpha 33 r_{-} \mathrm{R}$ & AAACtgctctttcagtgagcacaaT & \\
\hline \multirow[t]{2}{*}{3} & $\gamma 32 \mathrm{f} \_\mathrm{F}$ & TGGCAgctcgttgccctcgctctcc & 3C ( $\gamma$-KAFIRIN editing) \\
\hline & $\gamma 32 \mathrm{f} \_\mathrm{R}$ & AAACggagagcgagggcaacgagcT & \\
\hline \multirow[t]{2}{*}{4} & $\gamma 41 \mathrm{f} \_\mathrm{F}$ & TGGCAcctcgctctcctggctctcg & 4C $(\gamma$-KAFIRIN editing $)$ \\
\hline & $\gamma 41 \mathrm{f} \_\mathrm{R}$ & AAACcgagagccaggagagcgaggT & \\
\hline
\end{tabular}

an $\mathrm{A}$ was used as an additional 5'-terminal nucleotide in all gRNAs, because useful target motifs starting themselves with an A are not available in the targeted gene regions.

The principles of cloning target-specific derivatives of vector pSH121 are shown in Figure 3. The sequences of the generic and derived vectors pSH121 differ in size (12,396 bp and 12,199 bp, respectively). The design of forward (single strand) oligonucleotides was as follows: 5'-TGGCA (or G) N2-20-3'. The design of reverse single strand oligonucleotides was accordingly as follows: 5'-AAAC (complementary to N20-2) T (or C)-3'. A double-stranded nucleotide fragment for integration in pSH121 can be easily created by annealing these two complementary single-stranded oligonucleotides (see Table 3). The double-stranded insert fragment has sticky ends compatible with the BsaI-created DNA-ends of the linearized vector $\mathrm{pSH} 121$.

The cloning protocol included the following steps.

1) Plasmid pSH121 was digested with $B s a I$ (Eco31I) restriction enzyme to allow for the insertion of the target-specific insert. Restriction products of BsaI fragments $1227 \mathrm{bp}$ (SpecR) and 10,972 bp were separated on a 1\% agarose gel. The latter fragment was isolated and purified from the gel.

2) The assembly of the target-specific double-stranded (ds) oligonucleotide was performed by heating a mixture of an equimolar amount of each of the single-stranded $\mathrm{F}$ and $\mathrm{R}$ oligonucleotides followed by their annealing via slow cooling.

3) The assembled ds oligonucleotide was ligated using compatible overhangs with the 10,972 bp BsaI(Eco31I)-fragment of plasmid pSH121.

4) The ligation products were transformed into competent $E$. coli cells, which were then grown and selected on LB medium with kanamycin. The plasmids isolated from the selected colonies were cleaved using endonuclease MluI and then sequenced to confirm the presence of the insert.

5) Upon digestion using Sfil, the fragment containing expression units for gRNA and cas 9 was ligated with the SfiI-linearized vector B479p7oUzm, thereby combining all functional elements and both borders of the T-DNA. The resultant binary vector also carries a bacterial selectable marker gene conferring re- 
sistance to streptomycin and spectinomycin.

The correct insertion of the target-specific parts of the gRNA into pSH121 was verified by Sanger sequencing using the OsU3p-F3 sequencing primer GACAGGCGTCTTCTACTGGTGCTAC as shown in Figures 4-7.

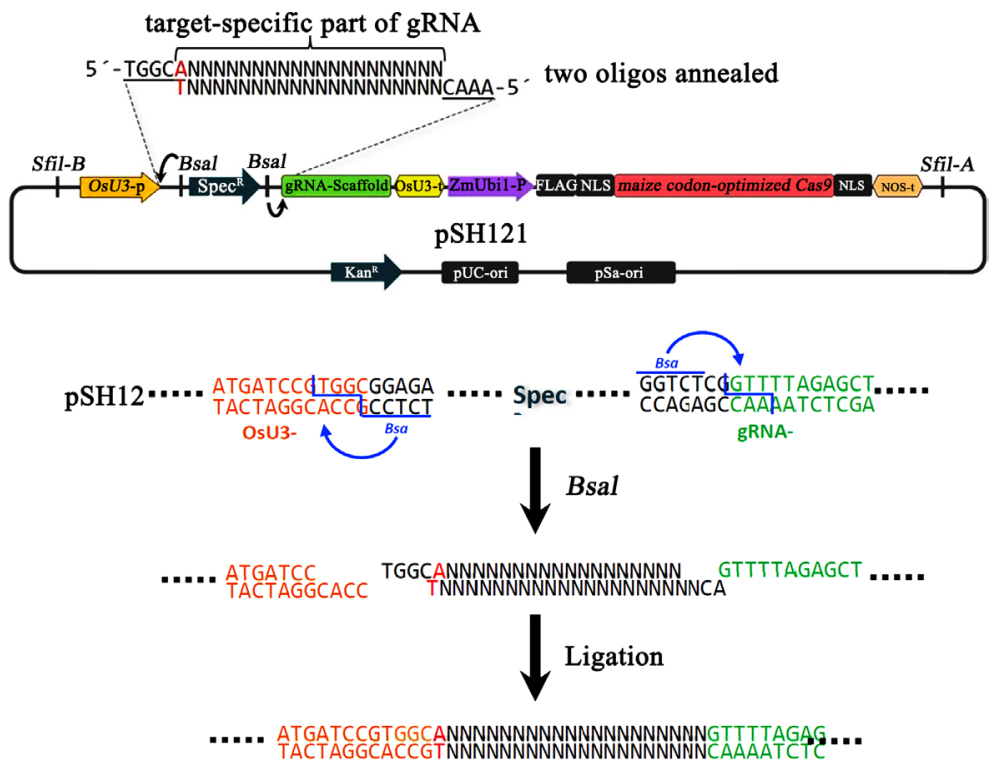

Figure 3. Workflow of inserting target gene-specific fragments into the generic vector pSH121.

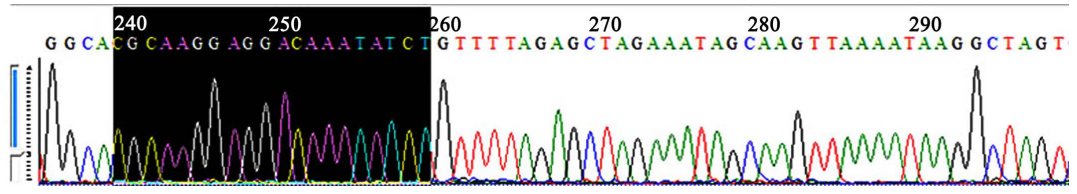

Figure 4. Confirmation by Sanger sequencing of the correct insertion of the target motif \#1 (a8)-specific part (indicated by black background) into the gRNA expression unit of pSH121 for the targeted mutagenesis of the $\alpha$-KAFIRIN gene.

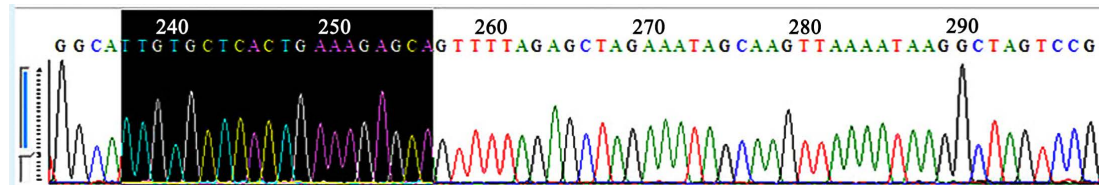

Figure 5. Confirmation by Sanger sequencing of the correct insertion of the target motif \#2 (a33)-specific part (indicated by black background) into the gRNA expression unit of pSH121 for the targeted mutagenesis of the $\alpha$-KAFIRINgene.

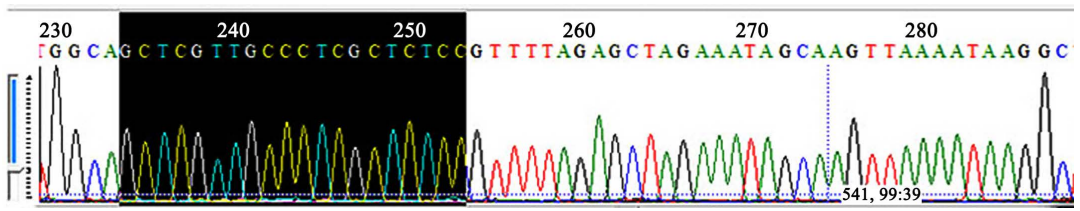

Figure 6. Confirmation by Sanger sequencing of the correct insertion of the target motif \#1 ( $\gamma 32$ )-specific part (indicated by black background) into the gRNA expression unit of pSH121 for the targeted mutagenesis of the $\gamma$-KAFIRINgene. 


\subsection{Restriction Analysis}

To control the successful assembly of binary vectors, restriction endonuclease analysis was performed using the enzymes $M l u I$ and SfiI. The MluI recognition site is unique in pSH121 and absent in B479p7oUZm-LH, while both of the generic vectors pSH121 and B479p7oUZm-LH have two SfiI restriction sites each. In Figure 8, digestion of each of the newly created vectors (1C, 2C, 3C, 4C) is displayed. The vectors have a size of $17,846 \mathrm{bp}$. Whereas MluI produced one fragment, cleavage with the SfiI yielded two fragments, the sizes of which correspond to the expected values (10,223 bp and $7623 \mathrm{bp})$.

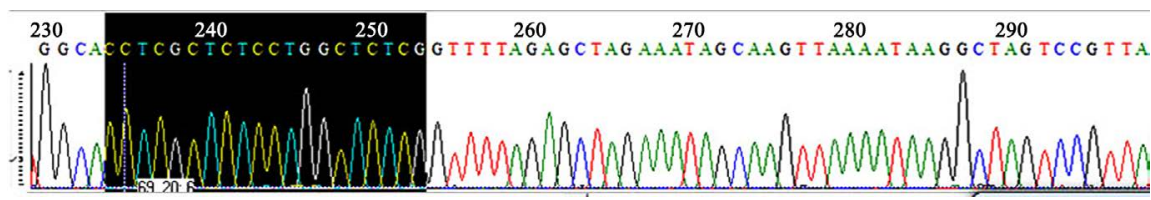

Figure 7. Confirmation by Sanger sequencing of the correct insertion of the target motif \#2 ( $\gamma 41$ )-specific part (indicated by black background) into the gRNA expression unit of pSH121 for the targeted mutagenesis of the $\gamma$-KAFIRIN gene.

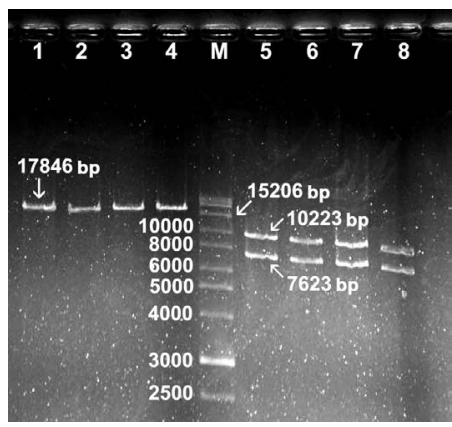

Figure 8. Restriction analysis of newly constructed binary vectors. Lanes 1 - 4: binary vectors $1 \mathrm{C}, 2 \mathrm{C}, 3 \mathrm{C}$ and $4 \mathrm{C}$ after digestion with MluI restriction enzyme; M-DNA fragment length marker ("SibEnzyme" Russia, cat. No. M30

http://russia.sibenzyme.com/info815.php); 5 - 8: binary vectors $1 \mathrm{C}, 2 \mathrm{C}, 3 \mathrm{C}$ and 4C after digestion with restriction endonuclease $S f i$.
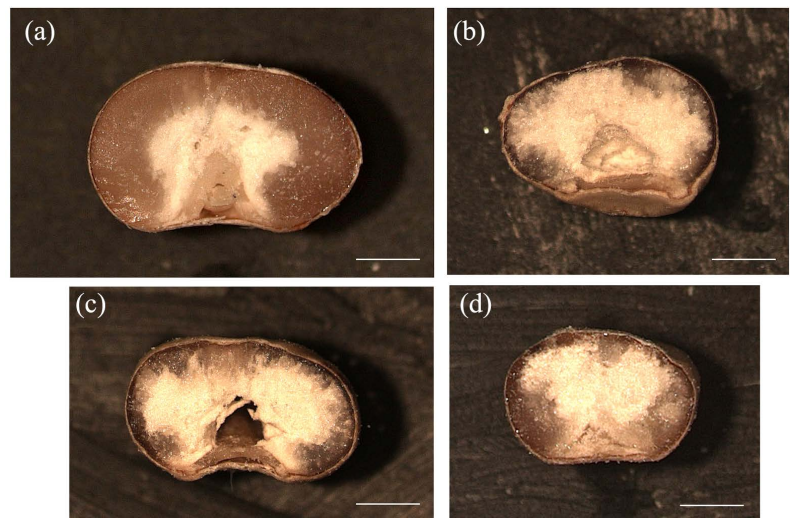

Figure 9. Cross sections of kernels set on the panicle of the sorghum plant \#2C-1.2.5 carrying a genetic construct for $\alpha$-KAFIRIN gene editing (target \#2C) ((b), (c), (d)) ((a)kernel of original cv. Avans). Bar $1 \mathrm{~mm}$. 


\section{Conclusion}

It is expected that the population of the Earth will reach 9.6 billion people by the middle of this century. The demand for staple crops thus will increase by up to $60 \%$ [22]. To cope with this challenge, a significant improvement of plant breeding and plant production methods is required. In this regard, genome editing belongs to the most promising approaches [23], with Cas endonucleases being the currently most powerful platform. Using this technology, the improvement of grain quality via targeted mutagenesis of the KAFIRIN genes of sorghum may be achieved in a comparatively short time [24]. The vectors we have created represent an important step towards this goal. One of these vectors, $2 \mathrm{C}$ for $\alpha$-KAFIRIN gene editing, was used to transform sorghum via Agrobacterium (strain AGL-0)-mediated DNA transfer to immature embryos of cv. Avans. In these experiments, we have obtained four plants ( $T_{0}$ generation) with modified endosperm texture (Figure 9) that should be expected in the case of disturbed synthesis of $\alpha$-kafirins, and improved in vitro digestibility of endosperm proteins [11] [12] [13] [21]. The incorporation of vectors during transformation was confirmed by PCR analysis. Amplification and sequencing of the target regions from the transgenic plants are in progress.

\section{Acknowledgements}

The work was funded in part by the Russian Foundation for Basic Research, grant 19-016-00117.

\section{Conflicts of Interest}

The authors declare no conflicts of interest regarding the publication of this paper.

\section{References}

[1] Koeppel, I., Hertig, C., Hoffie, R. and Kumlehn, J. (2019) Cas Endonuclease Technology-A Quantum Leap in the Advancement of Barley and Wheat Genetic Engineering. International Journal of Molecular Sciences, 20, Article No. 2647. https://doi.org/10.3390/ijms20112647

[2] Zhu, H., Li, C. and Gao, C. (2020) Applications of CRISPR-Cas in Agriculture and Plant Biotechnology. Nature Reviews Molecular Cell Biology, 21, 661-677. https://doi.org/10.1038/s41580-020-00288-9

[3] Zhang, Y., Massel, K., Godwin, I.D. and Gao, C. (2018) Applications and Potential of Genome Editing in Crop Improvement. Genome Biology, 19, Article No. 210. https://doi.org/10.1186/s13059-018-1586-y

[4] Kim, J. and Kim, J. (2019) New Era of Precision Plant Breeding Using Genome Editing. Plant Biotechnology Reports, 13, 419-421. https://doi.org/10.1007/s11816-019-00581-w

[5] Belton, P.S., Delgadillo, I., Halford, N.G. and Shewry, P.R. (2006) Kafirin Structure and Functionality. Journal of Cereal Science, 44, 272-286. https://doi.org/10.1016/j.jcs.2006.05.004

[6] Henley, E.C., Taylor, J.R.N. and Obukosia, S.D. (2010) The Importance of Dietary 
Protein in Human Health: Combating Protein Deficiency in Sub-Saharan Africa through Transgenic Biofortified Sorghum. Advances in Food and Nutrition Research, 60, 21-52. https://doi.org/10.1016/S1043-4526(10)60002-2

[7] Bean, S.R., Ioerger, B.P., Wilson, J.D., Tilley, M., Rhodes, D. and Herald, T.J. (2018) Structure and Chemistry of Sorghum Grain. In: Rooney, W., Ed., Achieving Sustainable Cultivation of Sorghum: Sorghum Utilization around the World, Vol. 2, Burleigh Dodds Science Publishing, Cambridge, 1-27.

https://doi.org/10.19103/AS.2017.0015.21

[8] Zhang, G. and Hamaker, B.R. (1998) Low A-Amylase Starch Digestibility of Cooked Sorghum Flours and the Effect of Protein. Cereal Chemistry, 75, 710-713. https://doi.org/10.1094/CCHEM.1998.75.5.710

[9] da Silva, L.S., Taylor, J. and Taylor, J.R. (2011) Transgenic Sorghum with Altered Kafirin Synthesis: Kafirin Solubility, Polymerization, and Protein Digestion. Journal of Agricultural and Food Chemistry, 59, 9265-9270.

https://doi.org/10.1021/jf201878p

[10] Kumar, T., Dweikat, I., Sato, S., Ge, Z., Nersesian, N., Chen, H., Elthon, T., Bean, S., Ioerger, B.P., Tilley, M. and Clemente, T. (2012) Modulation of Kernel Storage Proteins in Grain Sorghum (Sorghum bicolor (L.) Moench). Plant Biotechnology Journal, 10, 533-544. https://doi.org/10.1111/j.1467-7652.2012.00685.x

[11] Elkonin, L.A., Italianskaya, J.V., Domanina, I.V., Selivanov, N.Y., Rakitin, A.L. and Ravin, N.V. (2016) Transgenic Sorghum with Improved Digestibility of Storage Proteins Obtained by Agrobacterium-Mediated Transformation. Russian Journal of Plant Physiology, 63, 678-689. https://doi.org/10.1134/S1021443716050046

[12] da Silva, L.S., Jung, R., Zhao, Z., Glassman, K., Taylor, J. and Taylor, J.R.N. (2011) Effect of Suppressing the Synthesis of Different Kafirin Subclasses on Grain Endosperm Texture, Protein Body Structure and Protein Nutritional Quality in Improved Sorghum Lines. Journal of Cereal Science, 54, 160-167. https://doi.org/10.1016/j.jcs.2011.04.009

[13] Li, A., Jia, S., Yobi, A., Ge, Z., Sato, S.J., Zhang, C., Angelovici, R., Clemente, T.E. and Holding, D.R. (2018) Editing of an Alpha-Kafirin Gene Family Increases Digestibility and Protein Quality in Sorghum. Plant Physiology, 177, 1425-1438. https://doi.org/10.1104/pp.18.00200

[14] Kuluev, B.R., Gerashchenkov, G.A., Rozhnova, N.A., Baymiev, An.Kh., Vershinina, Z.R., Knyazev, A.V., Matniyazov, R.T., Gumerova, G.R., Mikhailova, E.V., Nikonorov, Yu.M., Chemeris, D.A., Baymiev, Al.Kh. and Chemeris, A.V. (2017) CRISPR/ Cas Genome Editing of Plants. Biomics, 9, 155-182. (In Russian)

[15] Kumlehn, J., Pietralla, J., Hensel, G., Pacher, M. and Puchta, H. (2018) The CRISPR/ Cas Revolution Continues: From Efficient Gene Editing for Crop Breeding to Plant Synthetic Biology. Journal of Integrative Plant Biology, 60, 1127-1153. https://doi.org/10.1111/jipb.12734

[16] Kuluev, B.R., Gumerova, G.R., Mikhaylova, E.V., Gerashchenkov, G.A., Rozhnova, N.A., Vershinina, Z.R., Khyazev, A.V., Matniyazov, R.T., Baymiev, An.Kh., Baymiev, Al.Kh. and Chemeris, A.V. (2019) Delivery of CRISPR/Cas Components into Higher Plant Cells for Genome Editing. Russian Journal of Plant Physiology, 66, 694-706. (In Russian) https://doi.org/10.1134/S102144371905011X

[17] Gerasimova, S.V., Korotkova, A.M., Hertig, C., Hiekel, S., Hoffie, R., Budhagatapalli, N., Otto, I., Hensel, G., Shumny, V.K., Kochetov, A.V., Kumlehn, J. and Khlestkina, E.K. (2018) Targeted Genome Modification in Protoplasts of a Highly Regenerable Siberian Barley Cultivar Using RNA-Guided Cas9 Endonuclease. Vavilov Journal of Genetics and Breeding, 22, 1033-1039. https://doi.org/10.18699/VJ18.447 
[18] Chemeris, D.A., Kiryanova, O.Yu., Gerashchenkov, G.A., Kuluev, B.R., Rozhnova, N.A., Matniyazov, R.T., Baymiev, An.Kh., Baymiev, Al.Kh., Gubaidullin, I.M. and Chemeris, A.V. (2017) Bioinformatic Resources for CRISPR/Cas Genome Editing. Biomics, 9, 203-228. (In Russian)

[19] Gerashchenkov, G.A., Rozhnova, N.A., Kuluev, B.R., Kiryanova, O.Yu., Gumerova G.R., Knyazev, A.V., Vershinina, Z.R., Mikhailova, E.V., Chemeris, D.A., Matniyazov, R.T., Baimiev, An.Kh., Gubaidullin, I.M., Baimiev Al.Kh. and Chemeris, A.V. (2020) Design of Guide RNA for CRISPR/Cas Plant Genome Editing. Molecular Biology (Moscow), 54, 24-42. https://doi.org/10.1134/S0026893320010069

[20] Green, M. and Sambrook, J. (2012) Molecular Cloning: A Laboratory Manual. 4th Edition, Vol. II, Cold Spring Harbor Laboratory Press, New York.

[21] Wu, Y., Yuan, L., Guo, X. and Messing, J. (2013) Mutation in the Seed Storage Protein Kafirin Creates a High-Value Food Trait in Sorghum. Nature Communications, 4, Article No. 2217. https://doi.org/10.1038/ncomms3217

[22] Tilman, D., Balzer, C., Hill, J. and Befort, B.L. (2011) Global Food Demand and the Sustainable Intensification of Agriculture. Proceedings of the National Academy of Sciences of the United States of America, 108, 20260-20264.

https://doi.org/10.1073/pnas.1116437108

[23] Vershinina, Z.R. Kuluev, B.R., Gerashchenkov, G.A., Knyazev, A.V., Chemeris, D.A., Gumerova, G.R., Baimiev, Al.Kh. and Chemeris, A.V. (2017) Evolution of Genome Editing Techniques. Biomics, 9, 245-270. (In Russian)

[24] Elkonin, L.A., Panin, V.M., Kenzhegulov, O.A. and Gerashchenkov, G.A. (2019) Improvement of Grain Sorghum Nutritive Properties Using Modern Genetic and Biotechnological Methods. Biotechnology and Plant Breeding, 2, 41-48. (In Russian) https://doi.org/10.30901/2658-6266-2019-3-o6 